\title{
Transcoelomic spread and ovarian seeding during ovulation: A possible pathogenesis of Krukenberg tumor
}

\author{
Bikash Shah, Wen-Hao Tang ${ }^{1, *}$ and Shammi Karn² \\ 1 Department of General Surgery, Zhong Da Hospital, Southeast University, Nanjing, 210009, Jiangsu, China \\ 2 Department of Gynecology and Obstetrics, Zhong Da Hospital, Southeast University, Nanjing, 210009, Jiangsu, China
}

\begin{abstract}
Krukenberg tumor is a metastatic ovarian tumor with its primary site being the gastrointestinal tract. The pathogenesis of Krukenberg tumor formation is still in its hypothetical stage though the current understanding suggests lymphatic, hematogenous and transcoelomic as the 3 major routes of metastasis. We believe transcoelomic spread in association with ruptured ovary during the monthly process of ovulation is the major route of metastasis.
\end{abstract}

Keywords: Krukenberg tumor; ovary cancer; metastasis; transcoelomic spread; ovulation

\section{Background}

Krukenberg tumor is a metastatic tumor of the ovary that originates from the gastrointestinal tract. The characteristic of this kind of tumor is the presence of mucin-filled signet ring cells, which account for at least $10 \%$ of the tumor [1]. The diagnostic criteria of the WHO are based on the pathological description by Serov and Scully for making the diagnosis of Krukenberg tumor [2]. The description states that the following features should be present: i. the presence of stromal involvement, ii. the presence of mucin producing neoplastic signetring cells and iii. ovarian stromal sarcomatoid proliferation.

Krukenberg tumor was first described the German pathologist Friedrich Ernst Krukenberg in 1896, but it was only 6 years later in 1902 Schlagenhaufer pointed out the true metastatic nature of the Krukenberg tumor [3]. It is difficult to know the precise incidence of ovarian metastasis. In general, Krukenberg tumor is a rare disease, only about $1 \%$ to $2 \%$ of all ovarian tumors are Krukenberg's but in some countries like Korea, Japan and China, where the incidence of stomach cancer is very high, this rare disease is not so un-common [4, 5]. In most Krukenberg tumor cases stomach is the main primary site. Some studies have shown stomach cancer to be the primary site in about $70 \%$ of Krukenberg tumor cases [4]. Gastric and colorectal cancers together account for almost entire $(90 \%)$ of the primary site for the origin of this tumor [4, 6]. The prognosis of a Krukenberg tumor is poor. The median survival period is only 14 months, since such metastasis involve rapid cell growth and proliferation [7]. Pathologically distinguishing Krukenberg tumor from a primary ovarian cancer is not always easy. But it is very important to clinically distinguish Krukenberg tumor from the primary ovarian cancers because the treatment protocols, chemotherapy response, and prognosis are significantly different between the two $[6,8]$. Complete metastasectomy provides survival benefit in selected cases. The route of metastasis of tumors originating from the gastrointestinal tract is still in the hypothetical stage. Although the mechanism of Krukenberg tumor formation remains inconclusive, the current understanding suggests three major possible pathways of metastasis: lymphatic, hematogenous, and transcoelomic metastasis. However, due to the detection of the original tumor at an advanced stage, the majority of the cases may involve mixed metastatic pathways. Lymphatic and hematogenous spread, especially lymphatic spread is widely believed to play the possible role in cancer metastasis from the primary gastrointestinal site to the ovaries. But here, we would like to discuss the role of transcoelomic spread and rupture in the ovary (wound) during ovulation providing favorable seeding site as a major route of metastasis [9].

\section{Our hypothesis}

Not very much, but some research has been done to understand the route of metastasis of Krukenberg tumor.

\footnotetext{
*Corresponding author: Wen-Hao Tang, Department of General Surgery, Zhong Da Hospital, Southeast University, Nanjing, 210009, Jiangsu, China. Tel.: 0086-13951083834/ 0086-25 83262311; Email: tang_wh26@126.com

Received 21 March 2016 Revised 5 May 2016 Accepted 13 May 2016 Published 21 May 2016

Citation: Shah B, Tang WH, Karn S. Transcoelomic spread and ovarian seeding during ovulation: A possible pathogenesis of Krukenberg tumor. J Cancer Res Ther. 2016; 4(2):19-20. DOI: 10.14312/2052-4994.2016-4

Copyright: (c) 2016 Shah B, et al. Published by NobleResearch Publishers. This is an open-access article distributed under the terms of the Creative Commons Attribution License, which permits unrestricted use, distribution and reproduction in any medium, provided the original author and source are credited.
} 
Still the definitive metastatic pathway of Krukenberg tumor is not fully understood. Therefore, it is in a hypothetical stage. Many hypothesis including lymphatic, hematogenous have been proposed and believed. Here we propose a hypothesis of transcoelomic spread and ruptured ovary during ovulation, which provide a seeding site for metastasizing tumor cells as the possible route of metastasis in Krukenberg tumor cases.

\section{Many evidence support our hypothesis}

1. Patients with Krukenberg tumors are mostly young females having functioning ovaries [7]. The prevalence of Krukenberg tumor is higher in premenopausal women than in postmenopausal women. The average age at diagnose being $40-46$ years $[6,8]$. It is believed by some researchers that the functioning ovary is prone to metastatic disease because the rich blood supply to the ovary is prone to hematogenous metastasis [10]. In addition, we hypothesize the reason for the metastatic spread of cancer cells to the functioning ovary to be rupture (wound) in the ovary every month during ovulation. Molecular biology associated with wound healing suggest this is a dynamic process that begins immediately following injury. Growth factors are released in the traumatized area, which promote cell migration into the wound area (chemotaxis) [11]. During the process of normal ovulation there is disruption of the ovarian surface epithelium during the release of an oocyte. After ovulation the disruption tends to repair gradually. During repair, invaginations of the epithelium result in crypts that can pinch off to form epithelial (cortical) inclusion cysts within the underlying stromal compartment. These inclusion cysts are widely believed to be the potential origin of epithelial ovarian cancer. Likewise tumor cells that gets detached form advanced primary tumor and transported throughout the peritoneal cavity by peritoneal fluid may get trapped in the disruption of the surface epithelium of the ovary. Thus the inclusion cysts within the stromal component after ovulation may include the metastatic tumor cells, which may start colonizing and result in Krukenberg tumor [12].

2. There is bilateral involvement of the ovary in majority of the Krukenberg tumor cases [6].

3. Krukenberg tumors are mostly bilateral but in the case of unilateral Krukenberg tumors, the right ovary is more often involved than the left one [6]. And, we also know as many studies have shown, the right ovary is more frequently involved in ovulation than the left ovary $[10,13-$ 15]. The fact that the right ovary is more often involved in the process of ovulation may be the reason for right ovarian involvement of Krukenberg tumor. Also fluid in the abdominal cavity tends to have greater drainage in the right side than to the left side. The reason for this is because the right paracolic gutter is much larger than the left paracolic gutter $[16,17]$. The mechanism may be same as the peptic ulcer perforation in which the right lower quadrant is most common area of secondary pain [18]. Wound on the ovary during ovulation in contact with larger volume of abdominal fluid containing carried away tumor cells may be the possible mechanism of Krukenberg tumor and also the reason why Krukenberg tumor is more common in the right ovary than in the left ovary.

4. The most important predictor of Krukenberg tumor is the T stage, i.e., the clinical stage, of the primary carcinomas.
Based on the T stages, the tumor cells could scatter more easily into the peritoneal cavity, facilitating transcoelomic spread [6]. And in the majority of the metachronous Krukenberg tumor cases, the primary tumor at the gastrointestinal tract are found to be in its advanced stage (T3 and T4), in which the primary tumor have already invaded the serosal layer [9]. Here we see most of the primary tumors in metachronous Krukenberg tumor cases are in its advanced stage. And in advanced stage of primary gastrointestinal tumors the most common way for cancer cells to metastasize is transcoelomic spread.

5. The process of transcoelomic seeding in which detached tumor cells that have already acquired all the necessary metastatic characteristics are merely transported via peritoneal fluid into the abdominal cavity to a new site. The flow of intraperitoneal fluid is directed by gravity to its most dependent sites [12]. As per human being we acquire standing position making ovary an easy access to detached tumor cells.

\section{Conflicts of interest}

Authors declare no conflicts of interest.

\section{References}

[1] Nakamura Y, Hiramatsu A, Koyama T, Oyama $Y$, Tanaka A, et al. A Krukenberg tumor from an occult intramucosal gastric carcinoma identified during an autopsy. Case Rep Oncol Med. 2014; 2014:797429

[2] Serov SF, Scully RE, Sobin LH. International histological classification of tumors. No. 9. Histological typing of ovarian tumours. WHO. Geneva. 1973; 1-56.

[3] Schlagenhaufer F. uberdas metastatisheovarialkarzinonnach knebs des magins, daimes und anderer bauchosjane. MonatschrfGeb v Gynaekol. 1902; 15:485

[4] Al-Agha OM, Nicastri AD. An in-depth look at Krukenberg tumor: an overview. Arch Pathol Lab Med. 2006; 130(11):1725-1730.

[5] Jiang R, Tang J, Cheng X, Zang RY. Surgical treatment for patients with different origins of Krukenberg tumors: outcomes and prognostic factors. Eur J Surg Oncol. 2009; 35(1):92-97.

[6] Jeung YJ, Ok HJ, Kim WG, Kim SH, Lee TH. Krukenberg tumors of gastric origin versus colorectal origin. Obstet Gynecol Sci. 2015; 58(1):32-39.

[7] Moghazy D, Al-Hendy O, Al-Hendy A. Krukenberg tumor presenting as back pain and a positive urine pregnancy test: a case report and literature review. J Ovarian Res. 2014; 7:36.

[8] Khan M, Bhatti RP, Mukherjee S, Ali AM, Gilman AD, et al. A 26-year-old female with metastatic primary gastrointestinal malignancy presenting as menorrhagia. J Gastrointest Oncol. 2015; 6(2):E21-25.

[9] Qiu L, Yang T, Shan XH, Hu MB, Li Y. Metastatic factors for Krukenberg tumor: a clinical study on 102 cases. Med Oncol. 2011; 28(4):15141519.

[10] Järvelä I, Nuojua-Huttunen S, Martikainen H. Ovulation side and cycle fecundity: a retrospective analysis of frozen/thawed embryo transfer cycles. Hum Reprod. 2000; 15(6):1247-1249.

[11] Ganapathy N, Venkataraman SS, Daniel R, Aravind RJ, Kumarakrishnan VB. Molecular biology of wound healing. J Pharma Bioallied Sci. 2012; 4(Suppl 2):S334-337.

[12] Tan DS, Agarwal R, Kaye SB. Mechanisms of transcoelomic metastasis in ovarian cancer. Lancet Oncol. 2006; 7(11):925-934.

[13] Fukuda M, Fukuda K, Andersen CY, Byskov AG. Right-sided ovulation favours pregnancy more than left-sided ovulation. Hum Reprod. 2000; 15(9):1921-1926.

[14] Check J, Dietterich C, Houck MA. Ipsilateral versus contralateral ovary selection of dominant follicle in succeeding cycle. Obstet Gynecol. 1991; 77(2):247-249.

[15] Lan KC, Huang FJ, Lin YC, Kung FT, Lan TH, et al. Significantly superior response in the right ovary compared with the left ovary after stimulation with follicle-stimulating hormone in a pituitary downregulation regimen. Fertil Steril. 2010; 93(7):2269-2273.

[16] Primary Surgery. Volume One: Non-trauma chapter 5 . The surgery of the stomach. Perforated gastric or duodenal ulcer. http://www.meb. uni-bonn.de/dtc/primsurg/docbook/html/x3617.html

[17] WiseGEEK. What are paracolic gutters? http://www.wisegeek.com/ what-are-the-paracolic-gutters.htm

[18] Holzheimer RG, Mannick JA. Surgical Treatment: Evidence-Based and Problem-Oriented. Andrew G Hill, M.D. Fracs. Management of perforated duodenal ulcer. Munich: Zuckschwerdt, 2001. 